\title{
Comparison of UK's Minor Ailments Scheme and US's retail clinic model: a narrative review
}

\author{
Aung Z. Win \\ Notre Dame de Namur University, Belmont, CA, USA
}

\begin{abstract}
There is a raising demand for unscheduled care in the United Kingdom. Minor Ailments Schemes (MAS) were introduced to reduce the burden of minor ailments on higher cost settings such as general practices and emergency departments. The number of visits for minor ailments at GPs often declined following the implementation of MAS. Retail clinics in America employ nurse practitioners (NPs) and physician assistants (PAs) who can diagnose and treat minor illness, and minor injuries. Similar to the retail clinics, MAS can merge with walk-in centres. PAs and NPs can take over some primary care workload from pharmacists to prevent the pharmacists from being overwhelmed with all their current duties. MAS can also initiate the development of telehealth service to accommodate the home-bound patients. MAS must continue to change and evolve to meet the current and future demands of health care.
\end{abstract}

Key words: Minor Ailments Scheme; pharmacy; retail clinic; United Kingdom; United States

Received 26 August 2015; revised 18 December 2015; accepted 22 February 2016;

first published online 15 March 2016

\section{Introduction}

Pharmacy health service research is rare compared with other health services. Community pharmacies are an under-utilized resource (Watson et al., 2015). In the United Kingdom, most community pharmacies are owned by large chains such as Lloyds Pharmacy, Boots the Chemist and Moss Pharmacy. Community pharmacists see over $90 \%$ of the population/year (Anderson, 2000). About $99 \%$ of UK's population can get to a pharmacy within $20 \mathrm{~min}$ and in the areas of highest social deprivation, this increases to almost $100 \%$, due to positive pharmacy care law (Eaton, 2008; Todd et al., 2015). In the most affluent areas, about $81 \%$ live near a pharmacy. On the other hand, $84.8 \%$ of the population lives within a $20 \mathrm{~min}$ walk of a General Practitioner's (GP's) office in England overall while the figure reduces to $19.4 \%$ in rural areas (Todd et al., 2015). The community pharmacy is the preferred location over a GP's

Correspondence to: Aung Zaw Win, Notre Dame de Namur University, 1500 Ralston Avenue, Belmont, CA 94002, USA. Email: aungzwin@gmail.com office, due to the ease of access (Todd et al., 2015). Pharmacy care is particularly vital in rural areas where primary care physician shortage is greater than urban areas. Furthermore, recruiting GPs to work in areas of high social deprivation is challenging and primary care is inadequate in such areas (Chenet and McKee, 1996; Todd et al., 2015). The UK doctors welcome the government plans to increase the role of pharmacists in diagnosing and treating minor illnesses (Eaton, 2008).

GPs can only allocate at most 10 min of their time/consultation, whereas pharmacists can see patients for $30 \mathrm{~min}$ or more (Deslandes et al., 2015). However, in practice, pharmacist can rarely devote $30 \mathrm{~min} /$ patient for acute unscheduled care. Most GPs have insufficient time to answer patients' questions about treatments (Petty et al., 2003). Patients view the pharmacist as someone who is easier to talk to than a GP and someone willing to spend more time with them (Hassell et al., 2000). Community pharmacists are sometimes patients' first point of contact with the health-care system. They act as referral agents to doctors and mediators to other health services, so they assume the gatekeeper role 
(Anderson, 2000). Pharmacists and nurses have supplementary and independent prescribing rights in the United Kingdom and no other country has such extended non-medical prescribing rights as the United Kingdom (Courtenay et al., 2012). Pharmacists can order and interpret some lab tests (Mossialos et al., 2015). There is a raising demand for unscheduled care in the United Kingdom (O'Cathain et al., 2007). Approximately $40 \%$ of GPs' time is spent dealing with minor illnesses and about $8 \%$ of visits to the Accident \& Emergency Departments (A\&E) are for minor illnesses (Bednall, 2003; Pumtong et al., 2011). Minor ailments cost the GPs $£ 2$ billion annually and Emergency Departments (EDs) £136 million annually (Paudyal et al., 2013). Minor Ailments Schemes (MAS) were introduced more than a decade ago to reduce the burden of minor ailments on higher cost settings such as general practices and EDs. The United Kingdom does not have a national MAS but there have been calls for nationwide service (Paudyal et al., 2011). A substantial potential cost savings can be made with the expansion of MAS nationally and in 2009, MAS saved $£ 112$ million for England alone (Paudyal et al., 2013). At present, the list of minor illnesses treated under the MAS differ depending on the location - for example, England and Ireland. Government policy is promoting community pharmacy as the preferred setting for the management of minor ailments (Pharmacy Research UK, 2014).

In America, retail clinics are located inside pharmacies. An estimated $10.6 \%$ of the total population lives within a 5-min driving distance of a retail clinic, whereas $28.7 \%$ of the population lives within a 10-min driving distance (Rudavsky, 2009). In total, $55 \%$ of the visits to emergency rooms in the United States are for nonemergencies (Herrick, 2007). One study found that the public can save $\sim \$ 4.4$ billion annually by visiting the retail clinics for certain conditions, instead of EDs (Weinick et al., 2010). The purpose of this review was to compare the UK's MAS with the US's retail clinic model. The health system needs in United Kingdom are changing, and the system must address cost, convenience and technological matters. The United Kingdom can benefit from looking at examples from other countries to help meet the current and future demands of health care.

\section{Methods}

A literature search was done using the search terms: 'Minor Ailments Scheme', or 'retail clinics', or 'minor ailments service', or 'community pharmacy', or 'pharmacy-based Minor Ailments Schemes', or 'walk-in clinics'. The search of electronic databases: MEDLINE, EBSCO, ScienceDirect and Google Scholar, was done for articles published between 1996 and 2015. An internet search was also carried out using the search terms. Only those articles where the study setting was in United Kingdom or United States were included in the review. Figure 1 shows the methods used for the narrative review.

\section{Results}

\section{UK's MAS}

MAS in UK are run by pharmacists. The key studies of UK's MAS are summarized in Table 1.
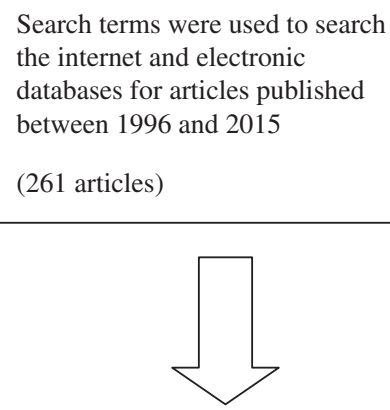

Articles with study setting in UK or US

(231 articles)

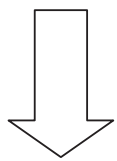

Articles that fit the objective of this narrative review and that contain the relevant information (38 references used)

Figure 1 Flowchart summarizing the steps used to screen information for the narrative review

Primary Health Care Research \& Development 2016; 17: 622-627 
Table 1 The key studies of UK's Minor Ailments Schemes (MAS)

\begin{tabular}{|c|c|c|}
\hline Studies & Year & Findings \\
\hline Watson et al. & 2015 & $\begin{array}{l}\text { MAS can deliver the same quality of } \\
\text { care as GPs and EDs }\end{array}$ \\
\hline $\begin{array}{l}\text { Mossialos } \\
\text { et al. }\end{array}$ & 2013 & $\begin{array}{l}\text { Pharmacists are often described as } \\
\text { the most accessible of all health } \\
\text { professionals and they have pre- } \\
\text { existing relationships with patients }\end{array}$ \\
\hline $\begin{array}{l}\text { Paudyal } \\
\text { et al. }\end{array}$ & 2013 & $\begin{array}{l}\text { The number of visits for minor } \\
\text { ailments at GPs often declined } \\
\text { following the implementation of } \\
\text { MAS. GPs are in favour of diverting } \\
\text { the care of minor ailments to } \\
\text { community pharmacists, and } \\
\text { extension of minor ailments } \\
\text { included in the schemes. Out of the } \\
\text { patients that utilized the schemes, } \\
>90 \% \text { were willing to reuse the } \\
\text { scheme }\end{array}$ \\
\hline $\begin{array}{l}\text { Wagner } \\
\text { et al. }\end{array}$ & 2011 & $\begin{array}{l}\text { The use of MAS is significantly } \\
\text { greater in socioeconomically } \\
\text { deprived areas and this contributes } \\
\text { to health equity }\end{array}$ \\
\hline $\begin{array}{l}\text { Naik } \\
\text { Panvelkar } \\
\text { et al. }\end{array}$ & 2009 & $\begin{array}{l}\text { MAS patients are likely to } \\
\text { recommend the services to others }\end{array}$ \\
\hline Eaton & 2008 & $\begin{array}{l}\text { The UK government estimates that } \\
\text { MAS can save GPs about } 57 \text { million } \\
\text { consultations a year }\end{array}$ \\
\hline Hassell et al. & 2000 & $\begin{array}{l}\text { Proxy users by a carer, friend or } \\
\text { relative can come to MAS for } \\
\text { consultations }\end{array}$ \\
\hline
\end{tabular}

The waiting time for a non-urgent GP appointment is approximately nine days and this is expected to increase further in the coming years (Todd et al., 2015). There is also a growth in waiting times for EDs (Royal Pharmaceutical Society, 2014a; 2014b; 2014c). No appointment is needed for MAS and the waiting times are short. They have extended hours including evenings and weekends. Examples of minor ailments included in the scheme are allergic rhinitis, pharyngitis, conjunctivitis, headache, haemorrhoids, diarrhoea, dyspepsia, cystitis, pain, respiratory tract infections, chickenpox, dermatitis and fungal infections (Paudyal et al., 2013). Patients can selfrefer to the MAS or they can be referred by a GP. The pharmacist can deal with minor ailments in three ways as follows: advice only, advice and supply of medicine, or referral to a GP. Pharmacists are reimbursed with a consultation fee and the cost of medicine supplied (Pumtong et al., 2011).
Table 2 The key studies of US's retail clinics

\begin{tabular}{|c|c|c|}
\hline Studies & Year & Findings \\
\hline $\begin{array}{l}\text { Shrank } \\
\text { et al. }\end{array}$ & 2014 & $\begin{array}{l}\text { Retail clinics can deliver quality care to } \\
\text { patients }\end{array}$ \\
\hline Stempniak & 2013 & $\begin{array}{l}\text { Hospital and clinic leaders stated that } \\
\text { retail clinics are helping to build a } \\
\text { continuum in patient care }\end{array}$ \\
\hline $\begin{array}{l}\text { Wilson } \\
\text { et al. }\end{array}$ & 2010 & $\begin{array}{l}\text { Almost } 50 \% \text { of Americans would } \\
\text { consider using a retail clinic }\end{array}$ \\
\hline Costello & 2008 & $\begin{array}{l}\text { Experts predict continual growth and } \\
\text { long-term viability of retail pharmacy } \\
\text { clinics in America }\end{array}$ \\
\hline Herrick & 2007 & $\begin{array}{l}\text { For those who have already used a retail } \\
\text { pharmacy clinic, } 96 \% \text { reported being } \\
\text { satisfied or very satisfied with their care }\end{array}$ \\
\hline
\end{tabular}

The cost of treating common ailments in community pharmacies is $£ 29.30$ /patient. The cost of treating the same problems at $A \& E$ is nearly five times higher at $£ 147.09 /$ patient and nearly three times higher at GP practices at £82.34/patient (Royal Pharmaceutical Society, 2014a; 2014b; 2014c). People who are exempt from National Health Service (NHS) prescription charges (elderly, pregnant and children) receive medicine at no cost through the scheme.

MAS complement GPs, and they do not compete with them. The schemes will allow GPs to spend more time on complex cases. The College of Emergency Medicine supports the minor ailment services (Royal Pharmaceutical Society, 2014a; 2014b; 2014c). Moreover, the schemes encourage self-care of minor illnesses. The report by the 'Self-Care Campaign' stated that promoting selfcare in patients can save the NHS $£ 10$ billion over the next five years (Self Care Forum, 2014). There is a lack of involvement of community pharmacists in telemedicine (Barr et al., 2012). Pharmacies can be a key resource in the field of connected health care in United Kingdom (Barr et al., 2012). Despite this, telehealth technologies are only being tested with GP practices (Barr et al., 2012).

\section{US's retail clinics}

Table 2 shows the key studies of US's retail clinics. Not all pharmacies have retail clinics but their numbers are increasing. Most are owned by retail pharmacy giants such as Walgreens, CVS, Wal-Mart, Rite Aid and Target. Retail clinics in America employ nurse practitioners (NPs) and 
physician assistants (PAs) who can diagnose and treat minor illness, and minor injuries (Gray, 2015). Patients of all ages can go to the retail clinics. They are $30-40 \%$ cheaper than physician offices and about 80\% cheaper than EDs (Ashwood et al., 2011). They have fixed prices for providing a particular treatment, and the price can be less if the patient has health insurance. Retail clinics have formed partnerships and affiliations with hospitals, patient centred medical homes and physician groups (CVS, 2015). After a visit, the PA sends a summary of the visit to the primary care doctor (CVS, 2015). Retail clinics are starting telemedicine programs, which will allow patients to be seen through a computer screen. Alternatively, patients can also come to a retail pharmacy and sit at a kiosk in a private room to interact with a health professional via video chat (CVS, 2015).

\section{Discussion}

This is the first review study to compare the UK's MAS with the US's retail clinics. There are many similarities as well as differences between the two models. In both countries, most of the pharmacies that offer primary care services are owned by large chains and corporations, and there are no doctors involved in patient care. The community pharmacies are situated in convenient locations, offering after-hours services. In addition, they have a similar list of minor ailments and both are created to relieve the burden of minor ailments on doctors and EDs. The cost of care at both places is cheap. They are also responsible for saving money for health systems. They do not compete with GPs or EDs. Both MAS and retail clinics can deliver quality care and receive high level of patient satisfaction. The main difference is that in America, the insurance or the patient pays for the service and in the United Kingdom, pharmacists are reimbursed by the NHS. Another difference is that MAS have the support of the UK government. Furthermore, in MAS, pharmacists treat minor illnesses, whereas PAs and NPs provide care in retail clinics.

Both health systems can learn from one another. Rather than implementing a range of different primary care services, it is better to consolidate the existing services. Both MAS and walk-in centres offer nearly identical services, with the exception of treating minor injuries and wound care. Some walk-in centres are led by GPs while some are led by nurses. Similar to the retail clinics, community pharmacy MAS can combine with walk-in centres and NPs and PAs can practice alongside pharmacists. All UK pharmacies offer essential services but advanced and enhanced services are optional. The MAS is just one of the many enhanced services and UK pharmacists are already performing many health services for the public. PAs and NPs can take over some primary care workload from pharmacists and this would prevent the pharmacists from being overwhelmed with all their current duties. With the use of kiosks, one NP or PA can cover several pharmacies. Patients can come to a community pharmacy and sit at a kiosk in a private room to talk to a NP or PA. Furthermore, skilled pharmacy technicians can support pharmacists in dispensing medications so that pharmacists can engage in other health services. It was found that the lower the number of medicines that pharmacists dispensed, the greater the number of other health services that they can carry out (Schafheutle et al., 2011).

At present, the staff at the walk-in centres are able to retrieve patients' records to update any treatment or advice given at the centre (Arain et al., 2013). The pharmacist should have access to patient medical records to safely prescribe medicines. So, by merging, MAS will be able to retrieve medical records, and communicate with GPs about a patient's visit, much like the retail clinics. This would promote continuity of care. The first pharmacy co-located with a walk-in centre opened in Merseyside in 2001 (Jesson and Wilson, 2003). There are now many pharmacists working in walk-in centres (Mason, 2000). More research is needed on the feasibility and practicality of combining walk-in centres and MAS. Moreover, as seen in retail clinics, MAS can form affiliations with hospitals, GP's offices, medical helplines such as NHS 111 and EDs. That way, more referrals can be made to MAS. Finally, following the example of retail clinics, MAS can initiate the development of telehealth services. Home-bound patients should have the option of videoconferencing with a pharmacist. One limitation of this study was that a full comparative analysis of efficiency and equity of the MAS and retail clinic models was not possible due to their differences. 


\section{Conclusion}

Community pharmacists should be increasingly involved in primary care. All things considered, the community pharmacy is a very suitable location for treating minor ailments. It is imperative that the public should be more aware of the services offered by the MAS. In conclusion, United Kingdom should have a national MAS offering identical services. The future holds great potential for the MAS but there is still room for growth. The schemes can learn from examples of health services from other countries. They must continue to change and evolve to meet the current and future demands of health care.

\section{Acknowledgement}

None.

\section{Financial Support}

This research received no specific grant from any funding agency, commercial or not-for-profit sectors.

\section{Conflicts of Interest}

The authors declare that they have no conflicts of interest.

\section{References}

Anderson, C. 2000: Health promotion in community pharmacy: the UK situation. Patient Education and Counseling 39, 285-91.

Arain, M., Nicholl, J. and Campbell, M. 2013: Patients' experience and satisfaction with GP led walk-in centres in the UK; a cross sectional study. BMC Health Services Research 13, 142.

Ashwood, J.S., Reid, R.O., Setodji, C.M., Weber, E., Gaynor, M. and Mehrotra, A. 2011: Trends in retail clinic use among the commercially insured. American Journal of Managed Care 17, e443-448.

Barr, P.J., McElnay, J.C. and Hughes, C.M. 2012: Connected health care: the future of health care and the role of the pharmacist. Journal of Evaluation in Clinical Practice 18, 56-62.

Bednall, R. 2003: Identification of patients attending accident and emergency who may be suitable for treatment by a pharmacist. Family Practice 20, 54-57.

Chenet, L. and McKee, M. 1996: Challenges of monitoring use of secondary care at local level: a study based in London, UK. Journal of Epidemiology \& Community Health 50, 359-65.

Primary Health Care Research \& Development 2016; 17: 622-627
Costello, D. 2008: A checkup for retail medicine. Health Affairs (Millwood) 27, 1299-303.

Courtenay, M., Carey, N. and Stenner, K. 2012: An overview of non medical prescribing across one strategic health authority: a questionnaire survey. BMC Health Services Research 12, 138.

CVS. 2015: Services, Rhode Island (RI). Retrieved 14 August 2015 from http://www.cvs.com/minuteclinic/services.

Deslandes, R., John, D. and Deslandes, P. 2015: An exploratory study of the patient experience of pharmacist supplementary prescribing in a secondary care mental health setting. Pharmacy Practice 13, 553.

Eaton, L. 2008: BMA welcomes expanded role for pharmacists. BMJ 336, 797.

Gray, E. 2015: CVS wants to be your doctor's office. TIME, p. 34. Accessed 1 January 2016.

Hassell, K., Rogers, A. and Noyce, P. 2000: Community pharmacy as a primary health and self-care resource: a framework for understanding pharmacy utilization. Health and Social Care in the Community 8, 40-49.

Herrick, D.M. 2007. Convenient care and telemedicine. Dallas, Texas: National Center for Policy Analysis.

Jesson, J. and Wilson, K. 2003: One-stop health centres: what co-location means for pharmacy. Health \& Place 9, 253-61.

Mason, P. 2000: NHS walk-in centres: implications for pharmacy. Pharmaceutical Journal 265, 305-7.

Mossialos, E., Courtin, E., Naci, H., Benrimoj, S., Bouvy, M., Farris, K., Noyce, P. and Sketris, I. 2015: From 'retailers' to health care providers: transforming the role of community pharmacists in chronic disease management. Health Policy 119, 628-39.

Mossialos, E., Naci, H. and Courtin, E. 2013: Expanding the role of community pharmacists: policymaking in the absence of policy-relevant evidence? Health Policy 111, 135-48.

Naik Panvelkar, P., Saini, B. and Armour, C. 2009: Measurement of patient satisfaction with community pharmacy services: a review. Pharmacy World \& Science 31, 525-37.

O'Cathain, A., Knowles, E., Munro, J. and Nicholl, J. 2007: Exploring the effect of changes to service provision on the use of unscheduled care in England: population surveys. BMC Health Services Research 7, 61.

Paudyal, V., Hansford, D., Cunningham, S. and Stewart, D. 2011: Pharmacy assisted patient self care of minor ailments: a chronological review of UK health policy documents and key events 1997-2010. Health Policy 101, 253-59.

Paudyal, V., Watson, M., Sach, T., Porteous, T., Bond, C., Wright, D., Cleland, J., Barton, G. and Holland, R. 2013: Are pharmacy-based minor ailment schemes a substitute for other service providers? British Journal of General Practice 63, 472-81.

Petty, D.R., Knapp, P., Raynor, D.K. and House, A.O. 2003: Patients' views of a pharmacist-run medication review clinic in general practice. British Journal of General Practice 53, 607-13.

Pharmacy Research UK. 2014: Community pharmacy management of minor illness: MINA study 2014. East Smithfield, London: Pharmacy Research UK. Retrieved 
14 August 2015 from http://www.pharmacyresearchuk. org/waterway/wp-content/uploads/2014/01/MINA-StudyFinal-Report.pdf.

Pumtong, S., Boardman, H. and Anderson, C. 2011: A multimethod evaluation of the pharmacy first minor ailments scheme. International Journal of Clinical Pharmacy 33, 573-81.

Royal Pharmaceutical Society. 2014a: College of Emergency Medicine supports pharmacy minor ailment services 2014. East Smithfield, London: Royal Pharmaceutical Society. Retrieved 14 August 2015 from http://www.rpharms.com/ pressreleases/pr_show.asp?id=2346.

Royal Pharmaceutical Society. 2014b: Improving urgent and emergency care through better use of pharmacists 2014 . East Smithfield, London: Royal Pharmaceutical Society. Retrieved 14 August 2015 from http://www.rpharms.com/ policy-pdfs/urgent-and-emergency-care.pdf.

Royal Pharmaceutical Society. 2014c: Pharmacists could save the NHS 1.1billion by treating common ailments 2014. East Smithfield, London: Royal Pharmaceutical Society. Retrieved 14 August 2015 from http://www.rpharms.com/ pressreleases/pr_show.asp?id=2342.

Rudavsky, R. 2009: The geographic distribution, ownership, prices, and scope of practice at retail clinics. Annals of Internal Medicine 151, 315-20.

Schafheutle, E., Seston, E. and Hassell, K. 2011: Factors influencing pharmacist performance: a review of the peer-reviewed literature. Health Policy 102, 178-92.

Self Care Forum. 2014: Case studies and practical advice 2014. Retrieved 14 August 2015 from http://www.selfcareforum.org/ wp-content/uploads/2011/07/SCWCaseStudyDocument.pdf.
Shrank, W.H., Krumme, A.A., Tong, A.Y., Spettell, C.M., Matlin, O.S., Sussman, A., Brennan, T.A. and Choudhry, N. K. 2014: Quality of care at retail clinics for 3 common conditions. The American Journal of Managed Care 20, 794-801.

Stempniak, M. 2013: Retail clinics: threat or opportunity? Hospitals \& Health Networks 87, 26-31.

Todd, A., Copeland, A., Husband, A., Kasim, A. and Bambra, C. 2015: Access all areas? An area-level analysis of accessibility to general practice and community pharmacy services in England by urbanity and social deprivation. BMJ Open 5, e007328.

Wagner, A., Noyce, P. and Ashcroft, D. 2011: Changing patient consultation patterns in primary care: an investigation of uptake of the Minor Ailments Service in Scotland. Health Policy 99, 44-51.

Watson, M., Ferguson, J., Barton, G., Maskrey, V., Blyth, A., Paudyal, V., Bond, C., Holland, R., Porteous, T., Sach, T., Wright, D. and Fielding, S. 2015: A cohort study of influences, health outcomes and costs of patients' healthseeking behaviour for minor ailments from primary and emergency care settings. BMJ Open 5, e006261.

Weinick, R.M., Burns, R.M. and Mehrotra, A. 2010: Many emergency department visits could be managed at urgent care centers and retail clinics. Health Affairs (Millwood) 29, 1630-636.

Wilson, A.R., Zhou, X.T., Shi, W., Rodin, H., Bargman, E.P., Garrett, N.A. and Sandberg, T.J. 2010: Retail clinic versus office setting: do patients choose appropriate providers? The American Journal of Managed Care 16, 753-59. 